\title{
A Contrastive Analysis of Explicit Cohesion in English Advertising Texts and Their Chinese Consecutive Interpretation Versions
}

\author{
Lan Zhou \\ Henan Polytechnic University, Jiaozuo, China; \\ The University of Auckland, New Zealand \\ Qiang Sun* \\ Henan Polytechnic University, Jiaozuo, China; \\ The University of Auckland, New Zealand
}

\begin{abstract}
Although much research has been conducted on language features of advertising, little has been reported on the contrast between language use in advertisements, particularly advertisements in English and those in Chinese. Drawing on Halliday and Hasan's theory about cohesion in text, this paper reports on the explicit cohesion devices used in advertising texts in English and Chinese. The data were derived from Singapore, a multilingual country where English and Chinese are two important languages. A total of thirty advertisements in English and their Chinese versions were analyzed for the distribution of explicit cohesive devices, i.e., lexical cohesion and grammatical cohesion. The study reveals that advertisements in English used more reference and conjunction devices than those in Chinese, whereas Chinese language advertisements employed more ellipsis devices than English language advertisements. It also finds that there were no differences in the use of substitution and lexical devices in English or Chinese language advertisements. The conclusion of the study is finally drawn and the further study is suggested.
\end{abstract}

Index Terms-grammatical cohesion, lexical cohesion, coherence, advertisement in English and Chinese, advertising

\section{INTRODUCTION}

Commercial advertising, according to Harris and Seldon (1962), is a public notice "designed to spread information with a view to promoting the sales of marketable goods and services" (p.40). Similarly, Arens, Weigold and Arens (2008) define advertising as "the structured and composed nonpersonal communication of information usually paid for and persuasive in nature about products, services or ideas by identified sponsors through the various media" (p.7). These definitions reveal that commercial advertising is a way of disseminating information, transmitted by means of the printed words or over the air, to the public, which aims to persuade people to take specific actions, for example buy a product or order a service. They also indicate that advertisements are usually paid for by a person, a group, an organization, or a business enterprise, to assist in achieving his or its goals. Since advertising plays a critical role in promoting sales of goods or services, it has attracted researchers' attention from multiple perspectives, such as business (Rossiter \& Percy, 1987), psychology (Snyder \& DeBono, 1985), culture (Cook, 2001; Vestergaard \& Schrøder, 1985), sociology (Wernick, 1991) and linguistics (Geis, 1982; Leech, 1966; Tanaka, 1994). This paper investigates the language of advertising, particularly language devices from the linguistic perspective. Linguistics choices are always carefully chosen by advertisers to attract potential consumers' attention. Substantial advertising is created in Englishwith advertising considered one of the most striking manifestations of English language (Graddol, 1997). Meanwhile, Chinese, spoken by around $20 \%$ of people worldwide, is likewise used by advertisers to attract Chinese speakers' attention. Language is the vehicle of advertising, along with the visuals. The choice of words, phrases and sentences and how sentences are connected becomes crucial in constructing advertising texts.

Today with the rapid development of global economic markets, and an awareness of the crucial role language plays in advertising, a critical issue is how to advertise commercial products or services globally and internationally. In order to make advertising reach more potential consumers in multicultural societies using a range of languages, advertising is usually produced bilingually or multilingually in order to achieve large scale sales globally. In this process, the appropriateness and elegance of the advertising language determines whether the advertising achieves its purposes. An interesting question arises as to whether different languages use the same language devices in advertising. In this paper, advertising in Singapore, compiled in both English and Chinese, was selected to investigate how English and Chinese advertising texts use explicit cohesion to construct their text structures. The focus of this paper is a comparison of

${ }^{*}$ Corresponding author 
cohesive devices used by the two languages.

\section{LITERATURE REVIEW}

Linguistic research on advertising has focused on the structures and functions of advertising language from several perspectives such as semantics (Emodi, 2011; Leech, 1966), pragmatics (Crook, 2004; Tanaka, 1994) and semiotics (Beasley \& Danesi, 2002). Leech (1966), one of the earliest advertising language researchers, asserted that the advertising language on British television was loose and ungrammatical. Later, Tanaka (1994) investigated the relationship between advertisers and readers by analyzing the language of written advertisementsin Britain and Japan. He argued that if an advertiser intentionally expressed a message in a way which triggered more than one interpretation, readers rejected the most accessible interpretation but searched for a more interesting interpretation. For example, using a pun in an advertisement catches readers' attention and stimulates the desire to purchase commercial products or services because it requires them to spend more time and energy in interpreting the language of the advertisement. Another study reported by Beasley \& Danesi (2002) called for an integration of semiotics into advertising studies to increase readers' understanding that advertising uses a persuasive rhetoric to realize its goals.

Other studies cited in Smith (2006) have examined the rhetorical figures of advertising language to attract consumers' attention and to encourage the purchase the goods or services advertised. For example, Cook (2001) identified several rhetorical figures which are frequently used in advertising material, such as metaphor, parallism, metonymy, and puns. Myers (1994) also identified alliteration, assonance, homophones, parallism and puns in the language of advertising. Smith (2006) reports a study of 45 English language advertisements and their translated Russian pairswhich detected examples of compensation, loss and addition in a corpus of 45 English-Russian advertisement pairs. Similarly, Maria Sidiropoulou (1998) also identified differences in both content, and linguistics devices employed, in the source and target language advertisements of 55 English-Greek advertisement pairs. There are also studies of advertisements in English and French (Kelly-Holmes, 2000), Spanish (Callow \& Gibran Mcdonald, 2005), Greek, Japanese and German (Piller, 2001), and Russian (Ustinova \& Bhatia, 2005).There is, however, a lack of research both on textual cohesion of advertising languages and advertisements in Chinese language. In order to remedy this gap, this paper reports on a study of the similarities anddifferences of cohesive devices used in English-Chinese pairs of advertisements.

\section{THEORETICAL FRAMEWORK}

\section{A. Concept of Cohesion}

The cohesion theory established by Halliday and Hasan (1976), was adopted as a framework to support the data analysis. As one of the linguistic features of a text, cohesion, together with coherence in discourse, is pivotal to the study of text linguistics and discourse analysis. Halliday and Hasan provided no direct and clear definition of cohesion but cited previous researchers' concept of cohesion contending that 'the concept of cohesion is a semantic one; it refers to relations of meaning that exist within the text, and that define it as a text. Cohesion occurs when the INTERPRETATION of some element in the discourse is dependent on that of another (p.4)." Cohesion is a linguistic device which ensures a text 'hangs together', and that components of the text, such as the words, are connected within a sequence. Cohesion contributes to coherence of a text.

\section{B. Classifications of Cohesion}

Halliday and Hasan (1976) not only initiated a framework of cohesion but generated categories of cohesive devices and their subdivisions. They established that there are two ways of creating cohesion in a text: grammatical cohesion and lexical cohesion.

Grammatical cohesion is based on structural content, which generally consists of reference, ellipsis, substitution and conjunction (Halliday \& Hasan, 1976). Reference is traditionally used in semantics to define the relationship between a word and what it points to in the context of situation or the surrounding text. However, in Halliday and Hasan's model, it refers to the relationship between two linguistic expressions. In the textual sense, reference occurs when audience or listeners have to retrieve the identity of what is being talked about by referring to another expression in the same context. Substitution and ellipsis operate in a relationship with the wording rather than the semantic meanings within texts. Substitution is divided into three types: a nominal, verbal, and clausal. For example, one can replace a noun, like a person, an apple and a toy; $d o$ is used to refer to a specific action, like hit, run, and sing, etc; so can refer to a clause. Since substitution is rarely found in the advertisements, it is not described in detail here. Ellipsis, interpreted as substitution by zero, is the omission of elements normally required by the grammar which a speaker/writer assumes are obvious from the text or the context and therefore need not be included. Ellipsis requires retrieving specific information that can be found in the preceding text. There are three types of ellipsis: nominal, verbal, and clausal. Conjunction refers to a type of semantic relationship in which what is to follow is systematically connected to what has gone before. It acts as a cohesive tie between clauses or sections of text in such a way as to demonstrate a meaningful pattern between them.

Lexical cohesion refers to the ties created between lexical elements, such as words, groups and phrases, which occur over long passages of a text or discourse (Halliday \& Hasan, 1976). Lexical cohesion usually refers to reiteration and collocation. Reiteration is a form of lexical cohesion which involves the repetition of a lexical item, at one end of the 
scale; and a number of things in between such as the use of a synonym, near synonym, or superordinate. Four main paradigmatic types of reiteration (meaning words of the same type or class) are repetition, synonymy, hyponymy, and meronymy. Collocation refers to lexical cohesion achieved through the association of lexical items that regularly cooccurbased on some kind of semantic relation to one another. There is always the possibility of cohesion between any pair of lexical items which are in some way associated with each other in the language. Collocation refers to the tendency of words to co-occur (p. 577). For example, when one sees the noun bicycle in a sentence, it is much likely that the verb ride will also appear in the same sentence.

\section{Cohesion and Coherence}

Coherence refers to underlying conceptual relations among parts of a text and despite some differences of opinion it is generally accepted that cohesion is a necessary, but not a sufficient, condition for the creation of text coherence (Halliday \& Hasan, 1976). Cohesion and coherence are two aspects of text and are frequently mentioned as a pair. Cohesion is the overt linkage on the textual surface, connecting the linguistic parts to a whole while coherence is the covert linkage of the conceptual meaning of the text, connecting the linguistic text to its cultural, personal and situational contexts. Writers use grammatical, lexical, andsemantic devices to connect linguistic units such as phrases, clauses, and sentences to create a coherent text. Cohesive devices are used to make a text more compact, facilitating the comprehension of the underlying semantic and logical relations.

\section{DATA AND METhodology}

\section{A. The Data}

Thirty English-Chinese advertisement pairs were selected from Singapore's most widely read national English newspaper, the Straits Times, and the most widely circulated national Chinese newspaper, 联合早报( Lian He Zao Bao). In order to be considered as a translation pair, the English and Chinese versions had to advertise the same product (mainly cosmetic products), with the same or similar graphics and written text.

\section{B. Methodology}

The thirty advertising samples selected from the two newspapers search were analyzed inductively using the theoretical framework of Halliday and Hasan's cohesion theory. Firstly, the advertising texts were transcribed and coded them according the linguistic devices employed. Then, the coded results were summarized and compared to investigate the similarities and differences between the Chinese and English versions in terms of the usage of lexical and grammatical cohesion devices. Finally, the possible explanations for differences and similarities in relation to Halliday and Hasan's categories of cohesion were discussed. The research findings are presented in the forthcoming section.

\section{RESEARCH FINDINGS AND DISCUSSION}

The analysis of the coding of thirty-paired advertisements is presented in Table 1.

TABLE 1

A TOTAL NUMBER OF COHESIVE LINGUISTIC DEVICES IN THIRTY-PAIRED ADVERTISEMENTS IN ENGLISH AND CHINESE

\begin{tabular}{l|l|l|l|l|l|l}
\hline Cohesive devices & Reference & Substitution & Ellipsis & Conjunction & Reiteration & Collocation \\
\hline English versions & 112 & 0 & 85 & 120 & 70 & 56 \\
\hline Chinese versions & 35 & 0 & 130 & 40 & 70 & 56 \\
\hline
\end{tabular}

The above table is interpreted as follows:

1. Selected English advertising samples employed reference and conjunction cohesive devices twice more than the Chinese paired sample.

2. Selected Chinese advertising samples employed ellipsis almost twice as often as the paired English advertising sample.

3. There was no evidence of substitution used in either the English or Chinese advertising paired samples.

4. Both English and Chinese advertising samples demonstrated the same number of reiteration and collocation devices to achieve lexical cohesion.

In advertising texts, a reference directs either inwardly to something within the linguistic context or outwardly to something in the real world such as an attached picture. A reference that directs to the external factors is also named as an exophoric reference since they cannot get interpreted by elements within the linguistic text. Exophoric personal or demonstrative references were evident in all of the thirty-paired samples, both English and Chinese advertisements. Twenty sevenof these samples (90\%) utilized exophoric references in the headline or body of the advertisements. Exophoric references in the headline play a key role in linking the picture and the headline. With them, the image in the illustration and the description in the verbal text are linked naturally and logically. The cohesive power lies, not between linguistic elements, but between the picture and the linguistic unit, that is, the verbal text and the visual context, enhancing cohesion within the advertising discourse as a whole. For example,

Sample 1, 
"She asked for smooth flawless skin, and I ensured that."

“她想拥有完美无暇的肌肤，我给了她百分之百的保证”

This newspaper advertisement is about a cosmetic product with a picture of a beauty attached. The beauty, looking healthy and energetic, is smiling with her hand gesturing, as if she is talking to someone. Readers can easily infer that she or 她 refers to the charming beauty in the picture. Cook (2001) has pointed out that the third person pronouns in advertising texts are possibly exophoric, referring to someone or something obvious to the participants in the context, or the common knowledge they shared. Another example,

Sample 2,

"Without Svenson, this is how I'd look today......"

“如果没有史云逊, 我可能变成这样......”

This is an advertisement with a picture of a handsome gentleman attached. It is not difficult to conclude that $I$ or “我” refers to the man in the picture attached with the advert. The quotation marks imply that a person is speaking for the product Svenson. The reference demonstrates the function and purpose of the advertisements, which is attracting potential customers to purchase a certain of products orservice. This advertisement uses a spokesperson to engage potential customers. A spokesperson, as Moriarty, Mitchell and Wells (2009) have pointed out, is often employed as an advertising technique to speak on behalf of the producttobuild credibility between the product advertised and readers.

Some personal references, such as we and you, referring the narrator and readers individually, are also used in advertisements to establish an intimate tie between advertisersand readers. As a result, readers may feel privileged and are willing to purchase the product advertised. A typical example representing this point is shown below.

\section{Sample 3,}

Go on to an expert like Beauty Express, here we have all the right facilities to help you achieve your desired shape, safety and effectively. Our professional aestheticians will recommend you special slimming programmes with diet control that let you relax while losing those excess pounds you will turn out healthy, fit and looking like a million dollars!

在快速美专业美容减肥中心, 我们有最精良的设备, 安全有效的帮助您得到梦摪以求的身段。我们的专业美 容师会推荐特设的瘦身与饮食计划, 让您轻轻松松的减去多余的体重, 您很快就会可以成为人人艳羡的健康健 美的对象。

The use of we and you here puts the narrator and readers together at the same standpoint, making readers feel more intimate with the narrator. This technique shortens the emotional distance between the advertiser and the target audience, focusing their attention on the product advertised. Cook's (2001) assertion, that the use of we and you is the most striking and most frequent feature contributing to the cohesion of advertising text, is evident here.

In both examples, exophoric references are used to direct attention outwardly to figures in the pictures and to the readers. Cook (2001) has argued that you in the advertisements has double exophoric involving reference to someone in the picture and to readers as well. When these references are translated from English into Chinese, they are usually translated equally and correspondingly. This probably explains why both English and Chinese advertisements tend to use references in the texts.

Further study indicates greater use of references, such as the relational pronouns, the personal pronouns and the demonstrative pronouns, in English advertisements than in Chinese versions. These pronouns are frequently used in English advertisements but not in Chinese versions. English pronouns denoting a relationship in a sentence are often missing from the Chinese version. For example,

\section{Sample 4,}

Eventually it all comes down to peace. The kind that you will relish coming home to.

虽处繁华兴盛的旺地, 却是绝非一般的宁静, 如此祥和静䠓的天地.

In this example, that plays the role of linking with the previous sentence. In Chinese, there is no word with the same function as that. Therefore, that is omitted in the Chinese version. An explanation is likely to be that English and Chinese belong to different language patterns, hypotaxis or parataxis, with English putting an emphasis on hypotaxis and Chinese on parataxis. Hypotaxis refers to the connection of words or sentences in linguistic ways, both lexical and morphological, while parataxis refers to the connection of words and sentences by their semantic and logical relations rather than the linguistic devices (Fawcett, 2003). The English language is basically hypotactic, which is dependent on subordinate constructions, or the relationship of the constructions are linked with connectives, while the Chinese language has the tradition of being paratacticwithout connectives used to create the cohesion between sentences. Readers of Chinese textshave no difficulty in comprehending the meaning as they refer to the contextual situation. This is demonstrated in the following example.

Sample 5,

Bella's new Zen Facial is a holistic and revitalizing experience for both your skin and your soul. Using a proven

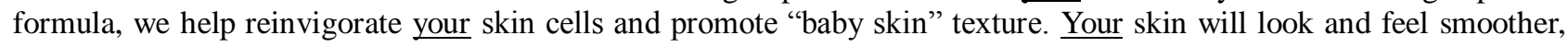
well-toned and younger.

Bella 全新 Zen Facial 护肤程序, 能将你的精神容颜及（你的）肌肤状态全面升华, 透过最新配方, 有效提高 (你的) 皮肤细胞活力, 加速新陈代谢, 让 (你的) 肌肤恢复出生婴儿般紧致顺滑, 黯哑色泽全面裉去, 面容再 


\section{现亮丽神采。}

In this example, three underlined your is not translated in the Chinese version. English tends to be hypotaxis which necessitates the repeated use of your showing the completeness of the texts. In contrast, belonging to the parataxis pattern, Chinese does not require the use of these pronouns to construct coherent texts.

There was no evidence of substitution used as a cohesive device in either the English and Chinese advertisements (see Table 1). Words signaling substitution, such as one, ones, the same, do, does, so, not, are not spotted in the samples. In order to convey accurate product information to potential consumers and to save the production costs, advertisement texts usually use brief, concise and accurate language (Huang, 2001). Substitution words are not utilized by advertisers because readers might find it difficult to identify the words to which they refer.

Ellipsis was identified in both English and Chinese advertisements analyzed as presented in Table 1. The use of ellipsis is a characteristic of both languages and advertising. The way that ellipsis used in the advertisements contributes to the coherence of the textis also seen in the following example.

\section{Sample 6,}

Costa Delsol comprises seven towers, each 30 storeys high set amid 430,000 sq. ft. of sprawling landscaped gardens. ( ) Forming two curvilinear crystalline waves. ( ) Sweeping gracefully across the beautiful landscaped estate, all seven towers rise in synchronicity to embrace the East Coast-Park, mirroring the waves of the South China Sea.

旭日湾共有七栋 30 层高的雄伟塔楼, 它们在面积 430, 000 平方英尺的翠绿庭园中, ( ) 组成两道晶莹剔透的 波浪逶迤伸展, () 既与东海岸公园相映成趣, () 同时也映照着中国海起伏的波浪, 创造出和谐动人的美景。

In the English version, seven towers is omitted in two places which are seen in brackets. In the Chinese version, 七栋 30 层高的雄伟塔楼 is also omitted in two places. Although ellipsis is used here, two advertisements are able to be understood by their readers thoroughly. What's more, if the phraseswere not omitted here, readers would feel the advertisement text was clumsy and repetitive.As Chinese is mainly a parataxis language, the clauses in the textare arranged one after the other without connectives showing the relationship between them. The omitted 七栋 30 层高的 雄伟塔楼 is retrieved from the hidden meaning of the neighboring sentences, and is, therefore, omitted in the text. Another explanation may be that the cost of advertising has to be taken into account when producing advertising. Advertisements are usually paid by the space or words and so, to minimize the cost. Advertisers tend to use succinct and informative expressionsespecially if the ellipsis does not affect the readers' acceptability of the text. Furthermore, using the ellipsis softens the tone of sentences, lessens the formalityof anadvertisement and shortens the distance between the product and readers. As Cook (2001) pointed out, lack of extensive ellipsis implies formality, social distance, distrust, or a lack of shared knowledge. Ellipsis creates an atmosphere of proximity and intimacy and, eventually, the potential consumers are motivated to purchase the product.

On further analysis, it was found that ellipsis is employed more frequently in Chinese advertisements than in English advertisements. An example of this point is illustrated as follows.

\section{Sample 7,}

When you hit 25, you start to blossom with feminine charm. But at this stage, your skin's ability to renew itself slows down. And your complexion is not as rosy and smooth as before. Your figure starts deteriorating and needs extra maintenance to keep it in top form.

女性过了 25 岁之后, (你) 开始散发成熟的女性韵味, 但 (你的) 代谢系统已经开始缓慢下来了, (你) 需要细心 呵护、保养，才能拥有更大的自信。

In this example, you and your in the English advertisement are omitted in the corresponding Chinese version. This is because Chinese is a parataxis language. The syntax of Chinese is featured by the arranging of clauses one after the other in a text. The subjects of clauses are usually omitted because they lie in the context and are easy to be inferred. Shen (1991) stated that the ellipsis of subjects reflected the Chinese philosophy of a harmony between nature and human beings. By contrast, English is a hypotaxis language which involves using connective words to express the meaning of texts.

Conjunctions were found in both the English and Chinese advertisements to express the usefulness of the products they advertised. For example,

\section{Sample 8,}

Fortunately, with Beijing 101's help I was able to attend my son's wedding in full crowning glory.

幸亏有北京 101 帮助我重获了头发, 高高兴兴地出席儿子的婚礼, 使我终身难忘。

Fortunately or 幸亏 claims that a user of the advertised product was appreciative of the effectiveness of this product. The advertiser here uses a quotation to enhance advocacy for the effectiveness of product. As Huang (2001) said, advertisers often use celebrities, well-known people or product users to assure the potential consumers of products' function. The conjunction words with this function are usually evident in Chinese advertisements.

There were, however, more conjunctions found in English advertisements than in their Chinese counterparts. The most frequent category of conjunctions in advertising discourse are additive, such as and. Advertisers prefer to use and to highlight the numerous merits the advertised product has. According to Halliday and Hasan (1976), and has the sense of "there is something more to be said" (p. 245), with which it can imply "The brand X not only...but also..." with an increase in degree.In Sample 3, the advertiser has listed three merits of the advertised product by using and to connect 
them. Hu (1994) said that using conjunctive words enabled readers to understand the semantic meaning in any types of texts. The use of conjunctions helps readers work out the meaning either within a sentence or between two sentences and therefore, is frequently used in advertisements in English. Chinese, however, is a paratactic language in which words and sentences are connected by their semantic and logical relations rather than linguistic devices. In the Chinese version of the above sample, and is omitted but the three merits of the products are still expressed in a coordinated manner. Another example,

\section{Sample 9,}

The therapy exfoliates the top layer of the skin with aluminum oxide microcrystals. And at the same time, it stimulates collagen and elastic production. The result was a smoother, firmer and evenly refined skin.

这种护理疗法是利用氧化铝微晶体来清理表皮,()同时加强胶原蛋白和弹力素的生长。

and in this advertisement is not translated in the Chinese version. The differences in the use of conjunctions between English texts and Chinese texts lie in two aspects-explicitness and implicitness (Zhu, Zheng \& Miao 2003). In other words, the implicit conjunction is usually adopted by Chinese advertisements, whereas explicit conjunction is preferred by English advertisements.

In all, conjunction plays a critical role in advertising text. First, they contribute to the coherence of the text. The roles that these conjunctive words play in the text are just like cement plays in the armored concrete, firmly and strongly. Second, a plethora of conjunctive words strengthen the function of advertising. Meanwhile, it is also revealed that conjunctive words in English advertisements playing the role of organizing the text are usually omitted in the Chinese version, while those words not only play the role of forming the text but take the aim of strengthening the effect of advertising promotion are usually rendered in the Chinese version. Here note that grammatical cohesive devices are discussed separately, and actually they are not independent from each other, and may co-occur in a text.

Finally, in regard to the lexical devices used in the advertising text, reiteration was found in all advertisements samples. This is not surprising as advertising particularly revolves around a product and its positive characteristics. This is evident in the advertisement below.

\section{Sample 10,}

"I lost all my hair after an illness and so my friend recommended me Beijing 101...All Beijing 101 products are made of $100 \%$ Chinese herbs and thus there are no side effects... Beijing 101 helped me regain my confidence once again...Fortunately, with Beijing 101's help I was able to attend my son's wedding in full crowning glory...I even recommended Beijing 101 to my brother who is suffering from thinning hair problems, I am a living testimony of their success!"

“去年的了一场病之后，我的头发完全脱光，幸好朋友介绍我到北京 101 护发中心...北京 101 护发中心制订 出适合我的 $100 \%$ 纯草药配方，以现代先进科技方法提炼制成，无副作用...我到北京 101 护发中心复诊...重获 头发, 恢复了以往的信心...幸亏有北京 101 帮助我重获了头发, 高高兴兴地出席儿子的婚礼...最近我也介绍有 脱发问题的弟弟到北京 101 护发中心, 因为我是护发成功的见证者。”

In this example, reiteration is frequently used in both English and Chinese advertisements. The product Beijing 101or 北京 101 护法中心 is repeated five times in order to deepen its impression on readers. For the same reason, the Chinese translation of Beijing 101, 北京 101 护发中心 is also repeated five times with a purpose of drawing readers’ attention to the product.

Collocation was frequently used in all the advertisements. In introducing a product, a plethora of vocabulary with similar meanings are employed in the advertisements. Thus, long cohesive chains were built up out of lexical relations of this kind. For example,

\section{Sample 11,}

Bella's new Zen Facial is a holistic and revitalizing experience for both your skin and your soul. Using a proven formula, we help reinvigorate your skin cells and promote "baby skin" texture. Your skin will look and feel_ smoother, well-toned and younger.

Bella 全新 Zen Facial 护肤程序, 能将你的精神容颜及肌肤状态全面升华, 透过最新配方, 有效提高皮肤细胞 活力, 加速新陈代谢, 让肌肤恢复出生婴儿般紧致顺滑, 黯哑色泽全面褪去, 面容再现亮丽神采。

In this cosmetics advertising, there are a series of words and phrases such as revitalizing, reinvigorate, smoother, well-toned and younger. These words are connected through a semantic relationship based on the cosmetic's functions and features. The advertiser has attempted to present the good qualities of the advertised product to readers so as to attract, and persuade them to purchase the product. The Chinese version uses the same lexical cohesive device, collocation, as the advertisement in English. Here, the collocations act as cohesive devices enhancing the role of the advertisement. Therefore, when translating the English advertisements to Chinese, similar collocations should be applied, that is taking account of vocabulary belonging to the same language groups and the practical traits of the textadvertising. Both English advertisements and Chinese advertisements belong to the same genre, sharing common similarities in achieving cohesion.

\section{CONCLUSIONS}

Based on the cohesion theory of Halliday and Hasan, the use of grammatical devices and lexical devices in thirty 
pairs advertisements for the same products in English and Chinese were compared in this study. The research findings reveal that while there are many common features in the usage of both grammatical devices and lexical devices, there are also differences in the construction of advertising texts. Both English and Chinese versions rarely used substitution and tend to use the same lexical devices including reiteration device and collocation device, whereas English versions used more references and conjunctions, but fewer ellipsis than Chinese versions. It is argued that, due to the hypotaxis of English and the parataxis of Chinese, English versions tend to use more reference and conjunction devices but fewer ellipsis device than Chinese versions. On the other hand, as advertisements, both English and Chinese versions have to keep the same features and possess the same goalsin advertising, some cohesive devices, such as substitution and lexical devices, were equally employed by two languages advertisements.

Studying the commonalities and differences of cohesive devices used by English and Chinese advertisements has some implications for producing advertisements in English and Chinese and English as a foreign language learning (EFL) and Chinese as a foreign language learning (CFL). Bearing the differences of cohesive devices used between English and Chinese advertisements in mind, advertisers enable to produce influent and comprehensible advertisements, further makes advertised products reach into potential target consumers as many as possible. Additionally, understanding the differences of cohesive devices between English and Chinese advertisements alerts EFL learners and CFL learners not to make mistakes in their construction of English texts and Chinese texts. They need to draw their attention to the differences of their first language (English or Chinese) and their targeted language (Chinese or English).

This paper reports and contrasts the usage of explicit cohesive devices in two languages, English and Chinese. The role of implicit cohesive devices such as context and social cultural factors underlying two languages are recommended for further study in English and Chinese advertising language.

\section{REFERENCES}

[1] Arens, W. F., Weigold, M. F., \& Arens, C. (2008). Contemporary advertising (11th ed.). Boston, MA: McGraw-Hill Irwin.

[2] Beasley, R., \& Danesi, M. (2002). Persuasive signs: The semiotics of advertising. Berlin, Germany: Walter de Gruyter.

[3] Callow, M., \& Gibran Mcdonald, C. (2005). The 'Spanglification' of advertising campaigns in hispanic media? A comparison of approaches in Spanish-only and dual language magazines. Journal of Marketing Communications, 11(4), 283-295.

[4] Cook, G. (2001). The discourse of advertising (2nd ed.). London, UK: Routledge.

[5] Crook, J. (2004). On covert communication in advertising. Journal of Pragmatics, 36(4), 715-738.

[6] Emodi, L. N. (2011). A semantic analysis of the language of advertising. African Research Review, 5(4), 316-326.

[7] Fawcett, P. D. (2003). Translation and language: Linguistic theories explained. Manchester, UK: St. Jerome.

[8] Geis, M. (1982). The language of television advertising. New York, NY: Academic press.

[9] Graddol, D. (1997). The future of English. London, UK: The British Council.

[10] Halliday, M. A. K., \& Hasan, R. (1976). Cohesion in English. London, UK: Longman.

[11] Harris, R., \& Seldon, A. (1962). Advertising and the public. London, UK: ANDRE DEUTSCH.

[12] Hu, Z.L (1994). Yupian de fenxi yu lianguan [Discourse Cohesion and Coherence]. Shanghai, China: Shanghai Foreign Language Education Press.

[13] Huang, G.W (2001). Yupian fenxi de lilun yu shijian-guanggao yupian yanjiu [Theory and Practice of Discourse Analysis: A Study in Advertising Discourse]. Shanghai, China: Shanghai Foreign Language Education Press.

[14] Kelly-Holmes, H. (2000). Bier, parfum, kaas: Language fetish in European advertising. European Journal of Cultural Studies, $3(1), 67-82$.

[15] Leech, G. (1966). English in advertising: A linguistic study of advertising in Great Britain. London, UK: Longmans.

[16] Moriarty, S., Mitchell, N., \& Wells, W. (2009). Advertising: Principles \& practice (8th ed.). Upper Saddle River, NJ: Pearson Prentice Hall.

[17] Myers, G (1994). Words in ads. London, UK: Arnold.

[18] Piller, I. (2001). Identity constructions in multilingual advertising. Language in Society, 30(02), 153-186.

[19] Rossiter, J. R., \& Percy, L. (1987). Advertising and promotion management. New York, NY: McGraw-Hill Book Company.

[20] Shen, X.L. (1991). Yuwen de chanshi [The Elucidation of Chinese]. Shenyang, China: Liaoning Education Press.

[21] Sidiropoulou, M. (1998). Advertising in translation: English vs. Greek. Meta: Translators 'Journal, 43(2), 191-204.

[22] Smith, K. (2006). Rhetorical figures and the translation of advertising headlines. Language and Literature, 15(2), $159-182$.

[23] Snyder, M., \& DeBono, K. G. (1985). Appeals to image and claims about quality: Understanding the psychology of advertising. Journal of Personality and Social Psychology, 49(3), 586-597.

[24] Tanaka, K. (1994). Advertising language. London, UK: Routledge.

[25] Ustinova, I. P., \& Bhatia, T. K. (2005). Convergence of English in Russian TV commercials. World Englishes, 24(4), 495-508.

[26] Vestergaard, T., \& Schrøder, K. (1985). The language of advertising. Oxford, UK: Basil Blackwell.

[27] Wernick, A. (1991). Promotional culture: Advertising, ideology and symbolic expression. Thousand Oaks, CA: Sage.

[28] Zhu, Y.S, Zheng, L.X., \& Miao, X.W. (2003). yinghan yupian duibi yanjiu[A Contrastive Study of Cohesion in English and Chinese Texts]. Shanghai, China: Shanghai Foreign Language Education Press.

Lan Zhou is a lecturer in Henan Polytechnic University, Henan province, China. She received her M.A degree in linguistics from Shanghai International Studies University, China in 2008. Currently, she is pursuing his PhD study in the Faculty of Education and Social Work, the University of Auckland, New Zealand. Her research interest includes language education and applied linguistics. 
Qiang Sun is a senior lecturer in Henan Polytechnic University, Henan province, China. He received his PhD degree in the Faculty of Education and Social Work, the University of Auckland, New Zealand. His research interest includes teacher education, language education and applied linguistics. 